\title{
The Quadrivalent Human Papillomavirus Vaccine in Recalcitrant Acral Warts: A Retrospective Study
}

Ling Yee Kuan, ${ }^{1} M B B S, M R C P(U K)$, FAMS (Dermatology), Sze Hon Chua, ${ }^{1} M B B S$, FRCP (Edin), FAMS (Dermatology), Jiun Yit Pan, ${ }^{1} M B B S, M C I$ (NUS), FRCP (Edin), Yik Weng Yew, ${ }^{1}$ MBBS, MPH (Harvard), Wee Ping Tan, ${ }^{1}$ MBBS, $M R C P(U K)$, FAMS (Dermatology)

\begin{abstract}
Introduction: The human papillomavirus (HPV) vaccine has been reported to lead to clinical clearance of lesions when used as an off-label treatment for recalcitrant extragenital warts. The aim of the study is to evaluate the therapeutic and adverse effects of HPV vaccine as an adjunctive therapy for treatment-resistant acral warts.

Methods: Patients with persistent warts despite first and second line therapies, and subsequently receiving the quadrivalent HPV vaccine between July 2013 and June 2016 as an adjunctive treatment for recalcitrant warts at the National Skin Centre, were included.

Results: Twenty-six patients with a median age of 34 years (range 8 to 77 years) were treated with the HPV vaccine. Nineteen (73.1\%) patients completed 3 doses of the vaccine, of whom $5(26 \%)$ achieved complete clearance, $8(42 \%)$ had partial clearance and $6(32 \%)$ did not respond to the vaccine. Among the 4 patients who received 2 doses of the vaccine, 3 (75\%) had complete clearance whereas $1(25 \%)$ had partial improvement of their warts. None of the patients reported adverse reactions.

Conclusion: Our study suggests a potential adjunctive role of the HPV vaccine in the treatment of acral warts recalcitrant to conventional therapy.
\end{abstract}

Ann Acad Med Singap 2020;49:749-55

Keywords: Acral warts, HPV vaccine, quadrivalent vaccine, recalcitrant warts

\section{Introduction}

Cutaneous warts are ubiquitous and cause significant disability worldwide. Hay et al. reported that viral warts were among the top 10 cutaneous conditions responsible for skin-related disability. The prevalence of viral warts was estimated to be 1,137 and 1,052 per 100,000 males and females, respectively, in

Southeast Asia. ${ }^{1}$

Ciconte et al. had also shown that acral warts had a significant impact on the quality of life, with $81.2 \%$ of patients feeling moderately to extremely embarrassed by their warts and $90.6 \%$ of patients frustrated by persistent warts. Furthermore, common and plantar warts posed significant inconvenience, with $24.7 \%$ of patients experiencing moderate to extreme difficulty in playing sports. ${ }^{2,3}$

Recalcitrant cutaneous warts are a therapeutic challenge. Patients with recalcitrant warts often would have been treated with a combination of cryotherapy, ablative or non-ablative laser treatments, surgical procedures, contact immunotherapy, oral cimetidine and topical treatments without being able to successfully eradicate them. In addition, patients may have to take significant time off from work or school for their treatment.

\footnotetext{
${ }^{1}$ National Skin Centre, Singapore

Address for Correspondence: Dr Ling Yee Kuan, National Skin Centre, 1 Mandalay Road, Singapore, 308205.

Email: lingyeekuan@nsc.com.sg
} 
Previous case reports and case series have demonstrated the involution of treatment-resistant warts in non-genital locations in response to the HPV vaccine. ${ }^{4-7}$ In this study, we cite our experience with this treatment modality.

\section{Methods}

\section{Study design}

A retrospective study of patients who received the quadrivalent vaccine against the human papillomavirus (HPV) as an adjunctive treatment for recalcitrant acral warts was conducted. All patients were treated for acral warts at the National Skin Centre, Singapore, over a 3-year period from July 2013 to June 2016. This study was conducted with the approval of the local Domain Specific Review Board (no. 2016/00764).

The HPV quadrivalent vaccine, Gardasil ${ }^{\circledR}$, contains HPV-like particles derived from the L1 capsid protein of HPV subtypes $6,11,16$ and 18 . Gardasil $\AA$ is administered at our centre as a 3-dose vaccination intramuscularly at 0,2 and 6 months after the first dose. Patients continued to receive ongoing first and second line treatments for their warts after starting the Gardasil ${ }^{\circledR}$ vaccine, owing to ethical consideration, as the use of this vaccine for extragenital warts was considered off-label.

The definition of recalcitrant wart in this study is, as described by Stender et al., treatment in vain by any method for more than 3 months. ${ }^{8}$ Inclusion criteria are as follows: (1) patients diagnosed with acral warts clinically by dermatologists at our centre and (2) persistent warts which failed to be eradicated after at least 3 months of first and second line treatments, including cryotherapy and/or topical therapies.

Patients without prior treatment or who had not received an adequate course of treatment of at least 3 months of cryotherapy and/or topical therapies were excluded from the study even if they had received the quadrivalent HPV vaccine for treatment. Patients with genital warts were excluded as our study sought to evaluate the efficacy of HPV vaccination as an adjunctive therapy for recalcitrant acral warts.

\section{Data collection}

All electronic patient records were reviewed to retrieve demographic data of patients (age, gender and ethnicity), disease duration and location of warts, previous and concomitant treatments other than the HPV vaccine, number of doses of the quadrivalent HPV vaccine, clinical status of the warts after receiving the HPV vaccine at follow-up visits. Any history of immunosuppression, such as recipients of solid-organ transplantation, haematological stem cell transplantation, human immunodeficiency virus infection or use of immunosuppressive medications such as chemotherapy, long-term corticosteroids or steroid-sparing agents, was recorded.

A complete response (CR) was defined as complete absence of verrucae with the presence of dermatoglyphics if located on the palmoplantar regions, while partial response (PR) was defined as a $50 \%$ or greater reduction in wart size or numbers. Patients with less than $50 \%$ improvement of their warts after receiving the HPV vaccine were considered to have not achieved significant response and labelled as non-responders (NR) in this study.

\section{Statistical analysis}

The statistical analyses were carried out using the statistical software STATA Version 14.2, StataCorp LLC, USA. Statistical significance was set at $P<0.05$. The Spearman's rank-order correlation was used to test the correlation between treatment response and each numerical characteristic such as age, disease duration, number of therapy sessions and duration of therapy. The Kruskal-Wallis $\mathrm{H}$ test was utilised to test the difference in treatment response across the groups.

\section{Results}

\section{Treatment and response}

A total of 26 patients received the HPV quadrivalent vaccine as an adjunctive treatment for their recalcitrant acral warts. Eight (30.8\%) out of the 26 patients showed a complete response, while $9(34.6 \%)$ patients demonstrated partial clinical clearance of their warts. However, another $9(34.6 \%)$ patients showed less than $50 \%$ improvement in their warts after receiving the HPV vaccine. The follow-up period after completion of the HPV vaccination ranged from 0 to 54 months, with a median of 6.5 months. The time to partial response from the first dose of the HPV vaccination ranged from 2 to 29 months, with a median of 6 months. The time to complete response from the first dose of the HPV vaccination ranged from 1 to 25 months, with a median of 8 months.

Baseline patient demographics, clinical characteristics and all treatments received prior to HPV vaccine are summarised in Table 1. We also analysed the concomitant treatments administered after the HPV vaccination in Table 2 to minimise the confounding effect of other treatments on the outcome measure.

Patients with complete clearance of their warts tended to be younger, with a median age of 27.5 years, as compared to 36 years and 38 years for the partial response 
Table 1. Baseline patient demographics, clinical characteristics and treatment received prior to their HPV vaccine, as categorised by their therapeutic response

\begin{tabular}{|c|c|c|c|c|}
\hline & Complete clearance of warts & Partial clearance of warts & No response & $P$-value \\
\hline $\begin{array}{l}\text { Number of Patients } \\
\text { (\% of all patients) }\end{array}$ & $8(30.8)$ & $9(34.6)$ & $9(34.6)$ & \\
\hline Male (\% in each group) & $(50)$ & $(66.7)$ & $(88.9)$ & 0.0875 \\
\hline $\begin{array}{l}\text { Median age } \\
\text { (range) in years }\end{array}$ & $27.5(14-44)$ & $36(8-77)$ & $38(21-64)$ & 0.2174 \\
\hline Race & & & & 0.246 \\
\hline $\begin{array}{l}\text { Chinese } \\
\text { (\% in each group) }\end{array}$ & $(87.5)$ & $(55.6)$ & $(66.7)$ & \\
\hline $\begin{array}{l}\text { Malay } \\
\text { (\% in each group) }\end{array}$ & $(12.5)$ & $(33.3)$ & 0 & \\
\hline $\begin{array}{l}\text { Indian } \\
\text { (\% in each group) }\end{array}$ & 0 & 0 & $(22.2)$ & \\
\hline $\begin{array}{l}\text { Others } \\
\text { (\% in each group) }\end{array}$ & 0 & (11.1) & $(11.1)$ & \\
\hline $\begin{array}{l}\text { History of non-genital warts which cleared } \\
\text { with treatment } \\
n=\text { number of patients ( } \% \text { in each group) }\end{array}$ & $2(25)$ & $3(33.3)$ & $2(22.2)$ & 0.8782 \\
\hline $\begin{array}{l}\text { Duration of current warts } \\
\mathrm{n}=\text { median number of months (range) }\end{array}$ & $14(6-72)$ & $25(6-156)$ & $27(6-96)$ & 0.3599 \\
\hline Location of warts & & & & 0.5647 \\
\hline $\begin{array}{l}\text { Hands } \\
n=\text { number of patients ( } \% \text { in each group) }\end{array}$ & $2(25)$ & $2(22.2)$ & $3(33.3)$ & \\
\hline $\begin{array}{l}\text { Feet } \\
\mathrm{n}=\text { number of patients }(\% \text { in each group })\end{array}$ & $4(50)$ & $4(44.4)$ & $5(55.6)$ & \\
\hline $\begin{array}{l}\text { Hands and face } \\
\mathrm{n}=\text { number of patients }(\% \text { in each group })\end{array}$ & $0(0)$ & $1(11.1)$ & $1(11.1)$ & \\
\hline $\begin{array}{l}\text { Hands and trunk } \\
\mathrm{n}=\text { number of patients }(\% \text { in each group })\end{array}$ & $1(12.5)$ & $0(0)$ & $0(0)$ & \\
\hline Median number of cryotherapy sessions (range) & $29(11-66)$ & $30(12-82)$ & $33(6-127)$ & 0.8509 \\
\hline $\begin{array}{l}\text { Duration of cryotherapy } \\
\mathrm{n}=\text { median number of months (range) }\end{array}$ & $13(6-72)$ & $24(6-38)$ & $14(6-35)$ & 0.6015 \\
\hline $\begin{array}{l}\text { Percentage of patients on topical salicylic acid, } \\
\text { (duration = months) }\end{array}$ & $62.5(1.5-30)$ & $66.7(1-24)$ & $88.9(2-65.5)$ & 0.2202 \\
\hline $\begin{array}{l}\text { Percentage of patients on topical antiproliferative } \\
\text { agents (duration }=\text { months) }\end{array}$ & $50(1.5-30)$ & $55.6(1-24)$ & $77.8(1.5-11)$ & 0.2405 \\
\hline $\begin{array}{l}\text { Percentage of patients on imiquimod } \\
\text { (duration = months) }\end{array}$ & 0 & 0 & $11.1(1.5)$ & 0.2294 \\
\hline $\begin{array}{l}\text { Percentage of patients on topical DCP } \\
\text { (duration = months) }\end{array}$ & 0 & $11.1(3.8)$ & $11.1(74.5)$ & 0.4143 \\
\hline $\begin{array}{l}\text { Percentage on patients on oral cimetidine (duration } \\
=\text { months) }\end{array}$ & $37.5(2-23)$ & 0 & $22.2(3-5.8)$ & 0.6048 \\
\hline $\begin{array}{l}\text { Percentage of patients who received ablative therapy } \\
\text { (duration = months) }\end{array}$ & $50(2-3)$ & $33.3(1)$ & $11.1(3)$ & 0.2202 \\
\hline
\end{tabular}

DCP: Diphenylcyclopropenone; HPV: Human papillomavirus 
Table 2. Summary of the number of doses of HPV vaccine and other treatment received after commencing vaccination for the 3 response groups

\begin{tabular}{|c|c|c|c|c|}
\hline & Complete clearance of warts & Partial clearance of warts & No response & $P$-value \\
\hline Median number of doses of vaccine received (range) & $3(2-3)$ & $3(2-3)$ & $3(1-3)$ & 0.7645 \\
\hline \multicolumn{5}{|l|}{ Number of patients who received: } \\
\hline $\begin{array}{l}1 \text { dose of HPV vaccine } \\
\mathrm{n}=\text { number of patients } \\
\text { (\% in each group) }\end{array}$ & $0(0)$ & $0(0)$ & $3(33.3)$ & \\
\hline $\begin{array}{l}2 \text { doses of HPV vaccine } \\
\mathrm{n}=\text { number of patients } \\
\text { (\% in each group) }\end{array}$ & $3(75)$ & $1(25)$ & $0(0)$ & \\
\hline $\begin{array}{l}3 \text { doses of HPV vaccine } \\
n=\text { number of patients } \\
(\% \text { in each group) }\end{array}$ & $5(26.3)$ & $8(42.1)$ & $6(31.6)$ & \\
\hline $\begin{array}{l}\text { Number of patients who received cryotherapy } \\
\text { (\% in each group) }\end{array}$ & $3(37.5)$ & $7(77.8)$ & $6(66.7)$ & 0.0473 \\
\hline $\begin{array}{l}\text { Median number of cryotherapy sessions } \\
\text { (range) }\end{array}$ & $4(2-5)$ & $11(3-29)$ & $23(1-47)$ & 0.1192 \\
\hline $\begin{array}{l}\text { Percentage of patients on topical salicylic acid } \\
\text { (duration = months) }\end{array}$ & $12.5(5)$ & $11.1(3)$ & $33.3(3-6)$ & 0.1743 \\
\hline $\begin{array}{l}\text { Percentage of patients on topical antiproliferative } \\
\text { treatment (duration }=\text { months) }\end{array}$ & 0 & $11.1(1)$ & $11.1(3)$ & 0.3182 \\
\hline Percentage of patients on DCP (duration = months) & 0 & 0 & $11.1(18)$ & 0.1923 \\
\hline Number of DCP doses received & NA & NA & 28 & NA \\
\hline $\begin{array}{l}\text { Percentage of patients on IL-MMR } \\
\text { (median number of doses) }\end{array}$ & 0 & $33.3(5-6)$ & 0 & 0.8894 \\
\hline $\begin{array}{l}\text { Percentage of patients on oral cimetidine } \\
\text { (duration = months) }\end{array}$ & 0 & $11.1(52)$ & 0 & 0.9389 \\
\hline Percentage of patients on ablative treatment & 12.5 & 0 & 11.1 & 0.9558 \\
\hline
\end{tabular}

DCP: Diphenylcyclopropenone; HPV: Human papillomavirus

and non-responder groups, respectively $(P=0.2174)$. Patients with complete response also showed a shorter median duration of wart disease of 14 months, as compared to 25 months and 27 months for patients from the partial response and non-responder groups, respectively, although this was not statistically significant $(P=0.3599)$.

\section{Number of warts, location and duration of warts}

There was no difference in the median number of warts at the start of the HPV vaccine study among patients with complete clearance of warts (median number of warts $=5$; range $1-15$ warts) as compared to patients with partial clearance of their warts (median number of warts $=5$; range 1-9 warts). Interestingly, the median number of warts in the non-responder group was lower at 3 (range 1-11 warts), yet this did not lead to a better response to the HPV vaccine.

In our study, 13 (50\%) of the patients had plantar warts, 7 (26.9\%) had warts on the hands, $3(11.5 \%)$ had warts on hands and feet, and $3(11.5 \%)$ patients had facial or truncal warts in combination with hand warts. None of the patients was immunosuppressed. Seven $(26.9 \%)$ out of 26 patients reported a history of non-genital warts which previously resolved but recurred.

There was no statistically significant difference in the baseline demographics between the patients who had complete, partial or no response to HPV vaccination in terms of age, gender, ethnicity and location of warts and previous history of warts. The observed difference in ages of the patients and duration of the wart 
disease among the 3 groups did not reach statistical significance either.

\section{Number of doses of the HPV vaccine received}

Among the 19 patients who received 3 doses of the HPV vaccine, 5 (26\%) patients had complete resolution of their warts while $8(42 \%)$ had partial resolution and 6 (32\%) had no significant improvement in their condition.

Complete clearance of warts was seen in $3(75 \%)$ patients and partial clearance observed in $1(25 \%)$ patient among the 4 patients who received 2 doses of the HPV vaccine. None of the 3 patients who received 1 dose of the HPV vaccine had any significant improvement of their condition.

\section{Treatments received prior to HPV vaccine}

A topical anti-proliferative agent, Verrumal ${ }^{\circledR}$, which contains 5 -fluorouracil $0.5 \%$ and salicylic acid 10\% solution, was used by a higher proportion of patients in the non-responder group, as compared to the complete and partial response groups $(\mathrm{CR}=50 \%$ versus $\mathrm{PR}=55.6 \%$ versus $\mathrm{NR}=77.8 \%$ ), prior to the HPV vaccine. In addition, a higher proportion of patients in the non-responder group had used topical salicylic acid $(\mathrm{CR}=62.5 \%$ versus $\mathrm{PR}=66.7 \%$ versus $\mathrm{NR}=88.9 \%$ ) prior to the HPV vaccination as compared to the patients from the complete and partial response group.

The median duration of use of Verrumal ${ }^{\circledR}$ was shorter in the non-responder group as compared to patients in the other 2 groups $(\mathrm{CR}=14.5$ months versus $\mathrm{PR}=4$ months versus $\mathrm{NR}=2.3$ months). Similarly, topical salicylic acid was used for a shorter median duration in the patients of the non-responder group as compared to the patients in the other 2 groups $(\mathrm{CR}=6$ months versus $\mathrm{PR}=5$ months versus $\mathrm{N}=3$ months).

Prior to the HPV vaccination, topical diphenylcyclopropenone (DCP) had been administered to 2 patients in this study to treat cutaneous warts. One patient in the partial response group received topical DCP for 3.8 months while a patient in the non-responder group received topical DCP for 74.5 months. One patient from the non-responder group applied topical imiquimod on alternate days for 7.5 weeks.

A total of 5 patients were given oral cimetidine. One patient who achieved complete response was prescribed cimetidine $400 \mathrm{mg} 3$ times a day for 8 weeks as she switched to ablative treatment. A patient from the nonresponder group was given cimetidine 400mg 3 times daily for 23 weeks, while 2 non-responder patients took cimetidine $600 \mathrm{mg} 3$ times a day for 12 and 14 weeks, respectively. One patient from the complete response group was given cimetidine $200 \mathrm{mg}$ twice daily for 3 weeks followed by $200 \mathrm{mg}$ for 96 weeks as he declined high-dose cimetidine due to potential side-effects.

The duration when patients were on cryotherapy and the number of sessions of cryotherapy received were not significantly different among the 3 groups of patients.

Clinical recurrence of warts occurred in all the patients in the 3 groups after their ablative treatment, although there was a higher proportion of patients who received ablative treatment in the complete response group as compared to the partial response and non-responder group $(\mathrm{CR}=50 \%$ versus $\mathrm{PR}=33.3 \%$ versus $\mathrm{NR}=11.1 \%)$. The observed differences in treatment given prior to the HPV vaccine among the 3 groups did not reach statistical significance.

\section{Treatments administered post-HPV vaccine}

A larger proportion of patients in the PR and NR groups required concurrent cryotherapy as compared to the patients in the $\mathrm{CR}$ groups $(\mathrm{CR}=37.5 \%$ versus $\mathrm{PR}=77.8 \%$ versus $\mathrm{NR}=66.7 \%$ ). This may be attributed to the incomplete clearance of warts in the PR and NR groups requiring them to have concurrent cryotherapy after the HPV vaccine. Patients who achieved CR status required fewer cryotherapy sessions as compared to patients in the $P R$ and NR group. $(\mathrm{CR}=4$ sessions versus $P R=11$ sessions versus $N R=23$ sessions).

Four patients from the partial response group received immunotherapy, among whom 3 received intralesional Measles-Mumps-Rubella vaccine injection (IL-MMR) and 1 received oral cimetidine $200 \mathrm{mg}$ once daily for 52 weeks, as he was concerned about potential side-effects of high-dose cimetidine as off-label treatment for warts. None showed complete response of their cutaneous warts despite additional immunotherapy. One patient from the NR group received immunotherapy in the form of topical DCP application to the warts. None of the patients in the CR group received immunotherapy.

\section{Discussion}

Viral warts constitute a significant clinical burden and morbidity among patients. ${ }^{1,9}$ While up to two-thirds of cutaneous warts resolve spontaneously in children within 2 years, ${ }^{10}$ the spontaneous resolution of warts in adults is slower, with some cases persisting up to 5 to 10 years. ${ }^{11}$ Warts present for a longer duration, and especially over plantar sites, are more treatment-resistant and less likely 
to clear spontaneously, thus beckoning the search for other treatment options. ${ }^{11,12}$ We acknowledge that there may be limitations to our definition of recalcitrant warts as described by Stender et al. ${ }^{8}$ as warts that persist beyond 3 months of conventional treatment might still resolve with continued conventional treatments. Also, given time, some warts might spontaneously resolve.

The HPV quadrivalent vaccine contains HPV-like particles derived from the $\mathrm{L} 1$ capsid proteins found in HPV subtypes 6, 11, 16 and 18. HPV-like particles are able to induce effective tumour-specific CD4+ and CD8+ T-lymphocyte signalling in patients with HPV-infected cells. ${ }^{7}$ Although common warts are caused by HPV subtypes 1, 2, 3 and 4, the homology of their L1 capsid proteins with those found in the HPV quadrivalent vaccine may result in cross-immunity against HPV subtypes of common warts. ${ }^{13}$ Thus, the HPV vaccine has been reported to elicit a B-cell and T-cell mediated immune response with the development of antibodies that crossneutralise other subtypes of HPV not contained within the HPV vaccine. ${ }^{13-17}$

A recent study by Yang et al. demonstrated that up to $46.7 \%$ and $16.7 \%$ of patients had complete resolution and partial resolution of cutaneous warts, respectively, after the quadrivalent HPV vaccine was administered as the primary treatment for warts, with no statistical difference in treatment response when adjusted for gender, age or duration of disease. ${ }^{18}$ Our study further supports an adjunctive role of the quadrivalent HPV vaccine for the treatment for recalcitrant warts that have persisted despite cryotherapy and local treatments. In our study, $30.8 \%$ of patients had complete resolution while $34.6 \%$ of patients had partial resolution of their cutaneous warts after receiving the HPV vaccine. None of the patients reported adverse reactions to the vaccine.

In our study, 13 patients had cutaneous warts for more than 2 years prior to receiving the HPV vaccination. Of these 13 patients, $3(23 \%)$ had complete resolution of their warts, $5(38.4 \%)$ had partial resolution, while another $5(38.4 \%)$ showed no improvement after receiving the HPV vaccine. In comparison, 5 (38.4\%) patients had complete resolution of their warts, $4(30.7 \%)$ had partial resolution of their warts and another $4(30.7 \%)$ showed no improvement among 13 patients with warts present for less than 2 years prior to receiving the HPV vaccine. Our results suggest that patients with a longer duration of wart disease may still benefit from the HPV vaccine as an adjunctive treatment for their recalcitrant warts, although patients with warts of less than 2 years in duration are more likely to experience complete clinical clearance after the HPV vaccine.
The limitations of our study include the lack of a placebo group and comparison with the bivalent HPV vaccine, small sample size, and the lack of measurement of HPV-specific antibodies in serum and HPV-subtyping of cutaneous lesions in our patients. Patients with complete resolution of their warts could not be followed up to evaluate recurrence rates owing to the retrospective nature of our study. Patients from the partial response and non-responder groups to the HPV vaccine continued to receive other treatments for their warts at our centre, which could have confounded our results. There were 7 patients $(26.9 \%)$ who did not complete the 3 doses of vaccine intended, which may have contributed to their partial or lack of response to HPV treatment. There is a possibility that the warts in our patients may have resolved spontaneously, but this is less likely considering their warts were not responsive to conventional treatment prior to receiving the HPV vaccine.

Nofal et al. published a study showing significantly better results, with $63.3 \%$ of 22 patients with recalcitrant warts showing complete clearance after undergoing intramuscular bivalent HPV vaccine. ${ }^{19}$ However, this study had important differences compared to our study participants, as our patients had hand and/or feet warts although they may also have concurrent warts elsewhere. Plantar warts tend to be more resistant to treatment than other non-genital sites probably due to the thick stratum corneum. ${ }^{11}$ The study by Nofal et al. also included warts present for more than 2 years which failed any 2 treatment modalities without a specific treatment duration, while our study only included those who failed the first 2 lines of treatment modalities, i.e. cryotherapy and topical therapies for a minimum duration of 3 months. Chronicity of warts does not equate to treatment-resistant warts. A prospective randomised head-to-head study comparing quadrivalent versus bivalent HPV vaccines should be conducted to evaluate if there is a difference in therapeutic outcomes for recalcitrant warts. ${ }^{19}$

Although previous studies have suggested that the HPV quadrivalent vaccine is more immunogenic in younger patients, ${ }^{20,21}$ it remains unclear which patients are more likely to completely clear their cutaneous warts with the HPV vaccine. In our study, those who were younger and with a shorter duration of wart disease were more likely to achieve complete clearance of their cutaneous warts with the HPV vaccine. However, the sample size may have precluded a statistically significant result. Cohort studies with larger sample sizes or 
randomised controlled clinical trials may therefore be useful to evaluate this novel adjunctive treatment for recalcitrant acral warts.

\section{Conclusion}

To our knowledge, this is the largest retrospective study on the use of HPV quadrivalent vaccine in the treatment of acral warts refractory to conventional therapies. Our study illustrates the real-life experience of treating such patients who subsequently underwent adjunctive off-label use of quadrivalent HPV vaccine to eradicate these warts. It demonstrated that the vaccine may be useful in a subset of patients with recalcitrant warts. However, as approximately one third of patients may not respond, patient selection and counselling are important before initiating treatment.

\section{REFERENCES}

1. Hay R, Johns N.E, Williams HC, et.al. The Global Burden of Skin Disease in 2010: An analysis of the prevalence and impact of skin conditions. J Invest Dermatol 2014;134:1527-34.

2. Ciconte A, Campbell J, Tabrizi S, et al. Warts are not merely blemishes on the skin: A study on the morbidity associated with having viral cutaneous warts. Australas J Dermatol 2003;44:169-73.

3. Lee SH, Pakdeethai J, Toh MPHS, Aw DCW. A double-blind, randomised, placebo-controlled trial of EMLA ${ }^{\circledR}$ cream (eutetic lidocaine/prilocaine cream) for analgesia prior to cryotherapy of plantar warts in adults. Ann Acad Med Singap 2014;43:511-4.

4. Silling $\mathrm{S}$, Wieland $\mathrm{U}$, Werner $\mathrm{M}$, et al. Resolution of novel humanpapillomavirus-induced warts after HPV vaccination. Emerg Infect Dis 2014;20:142-5.

5. Landis MN, Lookingbill DP, Sluzevich JC. Recalcitrant plantar warts treated with recombinant quadrivalent human papillomavirus vaccine. J Am Acad Dermatol 2012;67:e73-4.

6. Venugopal SS, Murrell DF. Recalcitrant cutaneous warts treated with recombinant quadrivalent human papillomavirus vaccine (types $6,11,16$, and 18) in a developmentally delayed, 31-year- old white man. Arch Dermatol 2010;146:475-7.
7. Abeck D, Folster-Holst R. Quadrivalent human papillomavirus vaccination: A promising treatment for recalcitrant cutaneous warts in children. Acta Derm Venereol 2015;95:1017-9.

8. Stender IM, Na R, Fogh H, et al. Photodynamic therapy with 5-aminolaevulinic acid or placebo for recalcitrant foot and hand warts: randomised double-blind trial. Lancet 2000;355:963-6.

9. Lim RBT, Lee HP. The art of public health in the context of a paradigm shift. Ann Acad Med Singap 2016;45:80-2.

10. Massing AM, Epstein WL. Natural history of warts. A two-year study. Arch Dermatol 1963;87:306-10.

11. Sterling JC, Gibbs S, Haque Hussain SS, et al. British Association of Dermatologists' guidelines for the management of cutaneous warts 2014. Br J Dermatol 2014;171:696-712.

12. Sterling JC, Handfield-Jones S, Hudson PM. Guidelines for the management of cutaneous warts. Br J Dermatol 2001;144:4-11.

13. Daniel BS, Murrell DF. Complete resolution of chronic multiple v erruca vulgaris treated with quadrivalent human papillomavirus vaccine. JAMA Dermatol 2013;149:370-2.

14. Barzon L, Squarzon L, Masiero S, et al. Neutralizing and crossneutralizing antibody titres induced by bivalent and quadrivalent human papillomavirus vaccines in the target population of organized vaccination programmes. Vaccine 2014;32:5357-62.

15. Ault KA. Human papillomavirus vaccines and the potential for crossprotection between related HPV types. Gynecol Oncol 2007;107:S31-3.

16. Slupetzky K, Gambhira R, Culp TD, et al. A papillomavirus-like particle (VLP) vaccine displaying HPV16L2 epitopes induce crossneutralizing antibodies to HPV11. Vaccin 2007;25:2001-10.

17. Pinto LA, Viscidi R, Harro CD, et al. Cellular immune responses to HPV-18,-31, and -53 in healthy volunteers immunized with recombinant HPV-16 L1 virus like particles. Virology 2006;353:451-62.

18. Yang MY, Son JH, Kim GW, Kim HS, et.al. Quadrivalent human papilloma virus vaccine for the treatment of multiple warts: a retrospective analysis of 30 patients. J Dermatol Treat 2019; 30:405-9.

19. Nofal A, Marei A, Ibrahim AM, Nofal E, Nabil M. Intralesional versus intramuscular bivalent human papillomavirus vaccine in the treatment of recalcitrant common warts. J Am Acad Dermatol 2020;82:94-100.

20. Giuliano AR, Lazcano-Ponce E, Villa L, et.al. Impact of baseline covariates on the immunogenicity of a quadrivalent (types $6,11,16$, and 18) human papillomavirus virus-like particle vaccine. J Infect Dis 2007;1968:1153-62.

21. Smolen KK, Gelinas L, Franzen L, et.al. Age of recipient and number of doses differentially impact human B and $\mathrm{T}$ cell immune memory responses to HPV vaccination. Vaccine 2012;30:3572-9. 